\title{
Shikonin-mediated inhibition of nestin affects hypoxia-induced proliferation of pulmonary artery smooth muscle cells
}

\author{
SUSU HE, JIAN LIN, LING LIN, YOUZU XU and JIAXI FENG \\ Department of Respiratory Medicine, Taizhou Hospital of Zhejiang Province, Linhai, Zhejiang 317000, P.R. China
}

Received November 3, 2017; Accepted May 21, 2018

DOI: $10.3892 / \mathrm{mmr} .2018 .9333$

\begin{abstract}
The imbalance between the proliferation and apoptosis of pulmonary artery smooth muscle cells (PASMCs) is of importance in pulmonary vascular remodeling. Shikonin, a naphthoquinone compound extracted from the Chinese medicinal herb Lithospermum erythrorhizon, inhibits the proliferation of rat smooth muscle cells (SMCs). The present study was designed to investigate the effects of shikonin on the proliferation of rat PASMCs and the possible mechanisms involved. Rat PASMCs were cultured under the following five treatment conditions: Normal control; hypoxia for $24 \mathrm{~h}$; hypoxia $+1 \mu \mathrm{M}$ shikonin for $24 \mathrm{~h}$; hypoxia $+2 \mu \mathrm{M}$ shikonin for $24 \mathrm{~h}$; and hypoxia $+4 \mu \mathrm{M}$ shikonin for $24 \mathrm{~h}$. The viability of PASMCs was measured using the Cell Counting Kit- 8 assay, the mRNA expression of nestin (NES) in each group was measured by reverse transcription-polymerase chain reaction and the protein expression of NES was measured by western blotting. The proliferation of hypoxic PASMCs transfected with NES-specific small interfering (si)RNA decreased compared with the non-transfected group. These results indicated that hypoxia induced the proliferation of PASMCs through the enhancement of NES expression. The treatment of hypoxic PASMCs with shikonin resulted in a significant downregulation of NES expression and the inhibition of PASMC proliferation.
\end{abstract}

\section{Introduction}

Pulmonary hypertension $(\mathrm{PH})$ is caused by pulmonary vasoconstriction, pulmonary vascular remodeling and in situ thrombosis (1). The condition leads to a progressive increase in pulmonary vascular resistance, resulting in the failure of the right side of the heart and, subsequently, the patient succumbs to hypertension sequelae. A previous study indicated that an

Correspondence to: Dr Jiaxi Feng, Department of Respiratory Medicine, Taizhou Hospital of Zhejiang Province, 150 Ximen Street, Linhai, Zhejiang 317000, P.R. China

E-mail: fjx_enzemed@163.com

Key words: pulmonary artery smooth muscle cells, nestin, hypoxia, shikonin, proliferation imbalance between the proliferation and apoptosis of pulmonary artery smooth muscle cells (PASMCs) affects pulmonary vascular remodeling (2). Therefore, investigations into the specific reversal mechanisms for PASMC proliferation are currently an important research topic for the treatment of $\mathrm{PH}$.

Nestin (NES), a member of the intermediate filament family, is expressed in myogenic and neural stem cells, vascular smooth muscle cells, and during the development of their immature descendants (3-5). A number of studies have demonstrated that NES participates in the development of endothelial cells during reparative angiogenesis and tumor vascularization. It is upregulated in the infarcted heart and detected in various types of cancer (6-8). NES has been used extensively as a marker for muscle and neural progenitor cells. The expression of NES decreases in muscle cells following the differentiation of skeletal muscles $(4,9)$, but is resumed in response to injury (10). Similar effects have been observed in the central nervous system (11). The reappearance of NES-positive cells in the neointima of balloon-injured carotid arteries has been demonstrated (5), which implicated NES-positive cells in the progression of vascular remodeling. Furthermore, a previous study of NES-RNA interference in an anti-Thy1 nephritis model reported that the knockdown of NES reduces the proliferation of mesangial cells following injury (12). These results indicated that the re-expression of NES may serve an important role in cell proliferation during the early post-injury phase. However, the expression of NES in PASMCs during the development of, and following injury has not yet been studied.

Shikonin, a natural naphthoquinone dye from the Chinese medicinal herb shikon (Lithospermum erythrorhizon), exerts multiple pharmacological activities in vitro and in vivo (13-15). It has been used as an anti-inflammatory (16) and anti-tumor agent (17) in traditional medicine for a long time. Previous studies have demonstrated that shikonin induces apoptosis in human cancer cells through the upregulation of p73 and the downregulation of E3 ubiquitin-protein ligase UHRF1 (18). Shikonin can also inhibit the proliferation and migration of endothelial (13) and vascular smooth muscle cells (19) in vitro. A recent publication reported that shikonin treatment significantly inhibits the morphology of glioma stem cells and NES positive $\left(\mathrm{NES}^{+}\right)$, sphere-forming cells and reduces CD133 expression (20). It is known that malignant gliomas have a perivascular location with certain $\mathrm{NES}^{+}$cells co-expressing CD133 (21). However, the function and association between 
NES and shikonin in hypoxic PASMCs have not been elucidated. Therefore, the aim of the present study was to test the hypothesis that shikonin-mediated downregulation of NES expression is the mechanistic basis of the inhibition of PASMCs proliferation.

\section{Materials and methods}

Reagents. Dulbecco's modified Eagle's medium (DMEM) was purchased from Gibco; Thermo Fisher Scientific, Inc. (Waltham, MA, USA). Fetal bovine serum (FBS) was obtained from Hyclone; GE Healthcare Life Sciences (Logan, UT, USA). Mouse monoclonal anti-NES antibody (clone 401; cat. no. 556309) was purchased from BD Biosciences (San Jose, CA, USA). Anti- $\beta$-actin antibody (cat. no. sc-58673) and anti-goat horseradish peroxidase (HRP)-conjugated secondary antibody (cat. no. sc-51625) were obtained from Santa Cruz Biotechnology, Inc. (Dallas, TX, USA). Shikonin was purchased from Shanghai Standard Technology Co., Ltd (Shanghai, China). The Cell Counting Kit 8 (CCK-8) was purchased from Dojindo Molecular Technologies, Inc. (Kumamoto, Japan). The synthesis of small interfering RNAs (siRNAs) was performed by Shanghai GenePharma Co., Ltd (Shanghai, China).

Cell preparation and culture. All experiments were performed in accordance with the National Institutes of Health (NIH) Guide for the Care and Use of Laboratory Animals (NIH publication no. 80-23) (22). The use of animals was conducted in strict accordance with the Guidance Suggestions for the Care of Laboratory Animals published by the Chinese Ministry of Science and Technology (23). All efforts were made to minimize animal suffering and to reduce the number of animals used in the study. In addition, all animal procedures in the present study were performed in accordance with the guidelines of the Wenzhou Medical University and the National Institutes of Health standards of animal care. The present study was approved by the Animal Ethics Committee of Wenzhou Medical University, including permit number SCXK (Zhejiang 2005-0019 150). A total of 15 10-week-old adult male Sprague-Dawley rats of specific pathogen free grade (weight 200-220 g) were purchased from the Laboratory Animal Center of Beijing (China). The rats (3-5 per cage) were kept in the same room for one week at a controlled temperature $\left(22-24^{\circ} \mathrm{C}\right)$ and relative humidity (50-60\%), under a 12-h light-dark cycle. Food and water were accessible. Prior to sacrifice, the rats were anesthetized by intraperitoneal injection of $500 \mathrm{mg} / \mathrm{kg} 5 \%$ chloral hydrate (Merck KGaA, Darmstadt, Germany). Anesthesia was monitored by electroencephalogram and rats were sacrificed by cervical dislocation following deep anesthesia. Rat death was confirmed by checking breathing, heartbeat, pupils and nerve reflex. Subsequently, the rats were immersed in $75 \%$ alcohol to disinfect the skin and then the chest was rapidly dissected. Primary cultures of PASMCs were obtained from the intrapulmonary arteries (grades 2-4 arterioles) of Sprague-Dawley rats using the method described by Gunther et al (24) with slight modifications. Briefly, the adventitia was stripped off by blunt dissection and the intimal surface was scratched to remove the endothelium. The remaining smooth muscles were placed in DMEM supplemented with 20\% FBS for 1-2 days to recover more cells following digestion. The pulmonary arteries were incubated in Hanks' balanced salt solution (Gibco; Thermo Fisher Scientific, Inc.) with $1.5 \mathrm{mg} / \mathrm{ml}$ collagenase I (Invitrogen; Thermo Fisher Scientific, Inc.) at $37^{\circ} \mathrm{C}$ for $90 \mathrm{~min}$. The cells were transferred to a $25 \mathrm{ml}$ culture flask and cultured in DMEM supplemented with 20\% FBS and 1\% penicillin-streptomycin solution at $37^{\circ} \mathrm{C}$ in an atmosphere of $5 \% \mathrm{CO}_{2}$. PASMC morphology was observed using an inverted microscope (TS100-F; Nikon Corporation, Tokyo, Japan) following $24 \mathrm{~h}$ of plating. After the PASMCs reached $80-90 \%$ confluence, the cells were harvested using trypsin (Promega Corporation, Madison, WI, USA) and passaged. The passaged cells were then recultured in DMEM supplemented with $10 \%$ FBS.

Immunofluorescence staining. Cells were seeded at $2 \times 10^{4}$ cells/ml and fixed using 4\% paraformaldehyde for $15 \mathrm{~min}$ at room temperature. After washing in PBS for three times, the cells were incubated with $10 \% \mathrm{H}_{2} \mathrm{O}_{2}$ in methanol for $10 \mathrm{~min}$ at room temperature to block endoperoxidase activity. Subsequently, the cells were immunolabeled with antibodies to smooth muscle- $\alpha$ actin ( $\alpha$-SMA; 1:100; cat. no. sc-53142; Santa Cruz Biotechnology, Inc.) by incubation overnight in a humid chamber at $4^{\circ} \mathrm{C}$. The sections were incubated with a fluorescein isothiocyanate (FITC)-labeled secondary antibody (1:100; cat. no. F9137; Sigma-Aldrich; Merck KGaA) at $37^{\circ} \mathrm{C}$ for 20-30 min in the dark and the nuclei were counterstained by incubation with DAPI (Sigma-Aldrich; Merck KGaA) at $37^{\circ} \mathrm{C}$ for 3-5 $\mathrm{min}$. The sections were observed and images were captured using a laser confocal microscope (Leica TCS SP2; Leica Microsystems $\mathrm{GmbH}$, Germany) at different excitation wavelengths (FITC: 450-490 nm and PI: 515-560 nm).

Cell treatments. The PASMCs used for all experiments were between passages 4 and 6. Cells seeded at a density of $1 \times 10^{4}$ cells $/ \mathrm{ml}$ were incubated in serum-free DMEM for $48 \mathrm{~h}$ to prevent growth. Hypoxia was induced through the incubation of cells in a $\mathrm{CO}_{2}-\mathrm{N}_{2}$ incubator (Heraeus Holding $\mathrm{GmbH}$, Hanau, Germany) in an atmosphere of $5 \% \mathrm{O}_{2} / 5 \% \mathrm{CO}_{2} / 90 \% \mathrm{~N}_{2}$. To study the effects of hypoxia and shikonin on PASMC proliferation and NES expression (mRNA level and protein level), PASMCs were divided into five groups: i) Normal: The cells were cultured in $10 \%$ FBS-DMEM in normoxic conditions $\left(21 \% \mathrm{O}_{2}, 5 \% \mathrm{CO}_{2}\right)$ for 24 h; ii) Hypoxia: The cells were cultured in 10\% FBS-DMEM in hypoxic conditions $\left(5 \% \mathrm{O}_{2}, 5 \% \mathrm{CO}_{2}\right)$ for $24 \mathrm{~h}$; iii) Hypoxia + $1 \mu \mathrm{M}$ shikonin: The cells were cultured in 10\% FBS-DMEM with shikonin $(1 \mu \mathrm{M})$ for $24 \mathrm{~h}$ in hypoxic conditions; iv) Hypoxia $+2 \mu \mathrm{M}$ shikonin: As for iii), but with $2 \mu \mathrm{M}$ ) and v) Hypoxia $+4 \mu \mathrm{M}$ shikonin: As for iv), but with $4 \mu \mathrm{M}$ shikonin. For the small interfering (si)RNA knockdown assay, PASMCs were divided into three groups: i) Blank control: The cells were cultured in $10 \%$ FBS-DMEM without NES-siRNA for $48 \mathrm{~h}$; ii) NES-siRNA: The cells were transfected with NES-siRNA for $48 \mathrm{~h}$; iii) Scrambled control: The cells were transfected with a scrambled negative control for $48 \mathrm{~h}$.

siRNA knockdown assay. The specific sets of gene sequences (Shanghai GenePharma, Co., Ltd.) for the siRNA knockdown assay include: NES-siRNA (sense) 5'-GGAGCAGAGAAU 
UGUGAAATT-3'; NES-siRNA (antisense) 5'-UUUCACAAU UCUCUGCUCCTT-3'; scrambled negative control (sense) 5'-UUCUCCGAACGUGUCACGUTT-3'; scrambled negative control (antisense) 5'-ACGUGACACGUUCGGAGAATT-3'. Prior to transfection, PASMCs were cultured at $4 \times 10^{4}$ and $1 \times 10^{4}$ cells/well in 6-well flat-bottomed plates and 96-well flat-bottomed microplates, respectively, until a confluence of 40-60\% was reached. Serum-free DMEM broth was used to dilute 100 pmol NES-siRNA (or scrambled negative control) and $5 \mu$ l Lipofectamine ${ }^{\circledR} 2000$ (Invitrogen; Thermo Fisher Scientific, Inc.) to $1 \mathrm{ml}$, respectively. The solutions were stored at $37^{\circ} \mathrm{C}$ for $5 \mathrm{~min}$ and then mixed and stored at $37^{\circ} \mathrm{C}$ for $20 \mathrm{~min}$ to form the siRNA/Lipofectamine 2000 mixture. The transfection mixture was added to the culture plates $(100 \mu \mathrm{l}$ per well in the 96-well microplates), incubated for $6 \mathrm{~h}$ and then replaced by DMEM medium. The effects of siRNAs were studied by reverse transcription-polymerase chain reaction (RT-PCR), western blotting and CCK-8 assays, which were performed $48 \mathrm{~h}$ post-transfection.

RNA extraction and semi-quantitative RT-PCR. Total RNA was isolated from the cells using TRIzol ${ }^{\circledR}$ (Gibco; Thermo Fisher Scientific, Inc.). The RNA concentration was determined by spectrophotometric measurements of the absorbance at a wavelength of $260 \mathrm{~nm}$. RT was performed using the first strand cDNA synthesis kit (Fermentas; Thermo Fisher Scientific, Inc., Pittsburgh, PA, USA) with total RNA (1 $\mu \mathrm{g})$ at $60^{\circ} \mathrm{C}$ for $5 \mathrm{~min}$. Subsequently, the sample was placed on ice for at least $1 \mathrm{~min}$. The reaction mixture was heated at $42^{\circ} \mathrm{C}$ for $60 \mathrm{~min}$ and $70^{\circ} \mathrm{C}$ for $5 \mathrm{~min}$ to inactivate the reverse transcriptase. The cDNA was subjected to PCR following the addition of $1 \mu \mathrm{l}$ first strand cDNA reaction mixture to a $25 \mu \mathrm{l}$ PCR reaction mixture. The specific sets of oligonucleotides for the PCR were: NES (sense) 5'-TGCTGAGTATGTCGTGGAG-3'; NES (antisense) 5'-GTCTTCTGAGTGGCAGTGAT-3'; GAPDH (sense) 5'-CACCTCAAGATGTCCCTTAGTC-3'; GAPDH (antisense) 5'-AAGTAGgGTGGTGAGGGTTG-3'. The PCR conditions comprised 30 cycles of amplification at $95^{\circ} \mathrm{C}$ for $30 \mathrm{sec}, 65^{\circ} \mathrm{C}$ for $30 \mathrm{sec}$ and $72^{\circ} \mathrm{C}$ for $1 \mathrm{~min}$, followed by a final extension period at $72^{\circ} \mathrm{C}$ for $10 \mathrm{~min}$. PCR amplifications were performed on ABI7500 real-time PCR detection system (Applied Biosystems; Thermo Fisher Scientific, Inc.). The PCR products (NES $5 \mu \mathrm{l}$ and GAPDH $2 \mu \mathrm{l}$ ) were subjected to electrophoresis on a $1.5 \%$ agarose gel and visualized by staining with ethidium bromide. The optical density (OD) of each band on the gel was measured using the Gelpro 31 system (Wenzhou Aoli Biomedical Instrument Factory, Shanghai, China). The OD values for NES were normalized to the OD values for GAPDH.

Western blot analysis. Total protein was extracted from cells using radioimmunoprecipitation assay lysis buffer (Beyotime Institute of Biotechnology, Shanghai, China) supplemented with $1 \mathrm{mM}$ phenylmethanesulfonyl fluoride (Beyotime Institute of Biotechnology) and protein concentration was quantified by the Bradford method against standard solutions of bovine serum albumin (BSA; Beyotime Institute of Biotechnology, Haimen, China). Equal quantities of protein $(50 \mu \mathrm{g})$ were separated using 8-12\% SDS-PAGE) gel electrophoresis (Bio-Rad Laboratories, Inc., Hercules, CA, USA).
The separated proteins were elecrophoretically transferred to a polyvinylidene fluoride membrane (EMD Millipore, Billerica, MA, USA). The membranes were blocked in Tris-buffered saline with $0.05 \%$ Tween 20 (TBST) containing 5\% BSA for $90 \mathrm{~min}$ at room temperature and then incubated with anti-NES (1:500; BD Biosciences) and anti- $\beta$-actin (1:1,000; Santa Cruz Biotechnology, Inc.) antibody at $4^{\circ} \mathrm{C}$ overnight. The membranes were washed with TBST buffer and incubated with HRP-labeled goat anti-mouse immunoglobulin G (1:1,000; Santa Cruz Biotechnology, Inc.) at room temperature for $60 \mathrm{~min}$. The HRP intensity was detected using a Pierce ${ }^{\mathrm{TM}}$ ECL Western Blotting Substrate kit (Pierce; Thermo Fisher Scientific, Inc.). The Quantity One software (version 4.4.0.36; Bio-Rad Laboratories, Inc.) was used to quantify the density of the bands.

Determination of cell proliferation. PASMCs were cultured at $1 \times 10^{4}$ cells/well in 96-well flat-bottomed microplates and incubated with $200 \mu 110 \%$ FBS-DMEM at $37^{\circ} \mathrm{C}$ and $5 \% \mathrm{CO}_{2}$ for 2 days ( 6 replicate wells were used for each group). At the end of the second day, the medium was replaced with $100 \mu \mathrm{l}$ fresh DMEM without FBS and treated in a similar manner for a further 2 days. CCK- 8 reagent $(10 \mathrm{ml} /$ well) was added to the wells at the end of the experiment and incubated at $37^{\circ} \mathrm{C}$ for $2 \mathrm{~h}$. The absorbance of the solution in each well at $450 \mathrm{~nm}$ was then determined using a microplate reader (ELX800; BioTek Instruments, Inc., Winooski, VT, USA).

Statistical analysis. The experimental data are expressed as the mean \pm standard deviation of three independent experiments. All data were subjected to normality tests. Comparisons of means among multiple groups were performed using one-way analysis of variance followed by Fisher's least significant difference post-hoc test. $\mathrm{P}<0.05$ was considered to indicate a statistically significant difference.

\section{Results}

Effects of hypoxia and shikonin on PASMC proliferation. Confluent PASMCs demonstrated typical hill and valley features (Fig. 1A), $\alpha$-smooth muscle actin is a commonly used marker of myofibroblast formation (25) and can be used to identify PASMCs. Immunofluorescence staining demonstrated that PASMCs were positively stained for $\alpha$-smooth muscle actin (Fig. 1B). A CCK-8 assay was used to determine whether shikonin inhibited the proliferation of hypoxic PASMCs (Fig. 2). The proliferation of cells in the hypoxia group was significantly increased compared with the normal group $(\mathrm{P}<0.05)$. Shikonin inhibited hypoxia-stimulated PASMC growth in a dose-dependent manner (Fig. 2). A significant decrease in cell proliferation was also observed in the hypoxia $+4 \mu \mathrm{M}$ shikonin group ( $\mathrm{P}<0.05$; Fig. 2).

Effects of hypoxia and shikonin on NES expression. NES expression was significantly increased in the hypoxia group compared with the normal group $(\mathrm{P}<0.05$; Fig. 3). Shikonin $(4 \mu \mathrm{M})$ significantly suppressed the expression of NES in hypoxic PASMCs $(\mathrm{P}<0.05)$.

RT-PCR was used to quantify the relative levels of NES expression in PASMCs with GAPDH mRNA used as the 

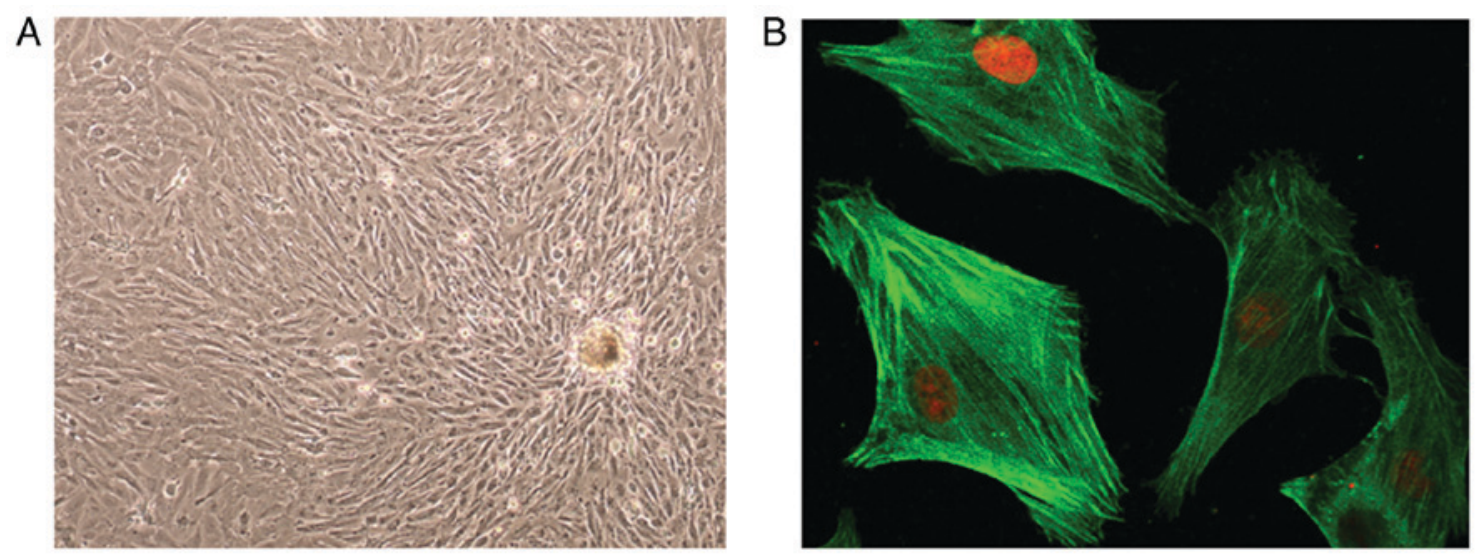

Figure 1. PASMC morphology and growth. (A) Typical 'hill and valley' appearance of PASMCs observed using phase contrast microscopy at a magnification, x400. (B) Positive immunofluorescent identification of $\alpha$-smooth muscle actin. PASMCs, Pulmonary artery smooth muscle cells.

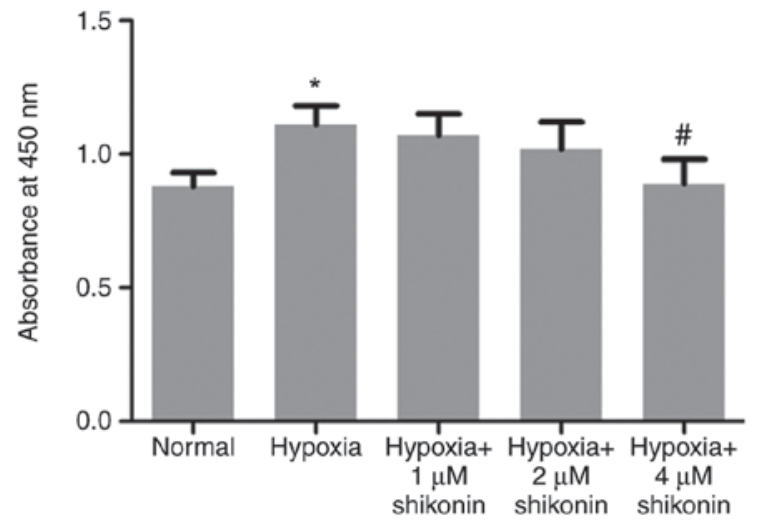

Figure 2. Effect of hypoxia and shikonin on cell proliferation. Pulmonary artery smooth muscle cells were cultured for $24 \mathrm{~h}$ in normoxic or hypoxic $\left(5 \% \mathrm{O}_{2}\right)$ conditions in the presence and absence of shikonin. The cell viability was determined using the Cell Counting Kit- 8 . ${ }^{*} \mathrm{P}<0.01$ vs. the normal and ${ }^{\text {"}} \mathrm{P}<0.01$ vs. the hypoxia groups, $\mathrm{n}=6$.

loading control. The expression of NES in the hypoxia group was significantly increased compared with the normal group ( $\mathrm{P}<0.05$; Fig. 4). Shikonin $(4 \mu \mathrm{M})$ significantly inhibited the expression of NES in hypoxic PASMCs at $24 \mathrm{~h}$ following treatment $(\mathrm{P}<0.05)$.

NES participates in PASMC proliferation. To determine the role of NES in PASMC proliferation, the cells were transfected with scrambled siRNA and Nes siRNA. The expression of NES $(\mathrm{P}<0.05$; Fig. 5) and Nes mRNA ( $<<0.05$; Fig. 6) was significantly suppressed by Nes RNAi. The CCK-8 assay indicated that the proliferation of NES-depleted cells was significantly decreased $(\mathrm{P}<0.05$; Fig. 7).

\section{Discussion}

Chronic hypoxia is the most important cause of $\mathrm{PH}$, a chronic obstructive pulmonary disease with a central role in the development of pulmonary heart disease (26). Long-term hypoxia can lead to hypoxic pulmonary vasoconstriction, dysfunction of the pulmonary vascular endothelium and pulmonary vascular remodeling, which culminates in PH. PASMCs can be divided into three phenotypes based on structure and function:
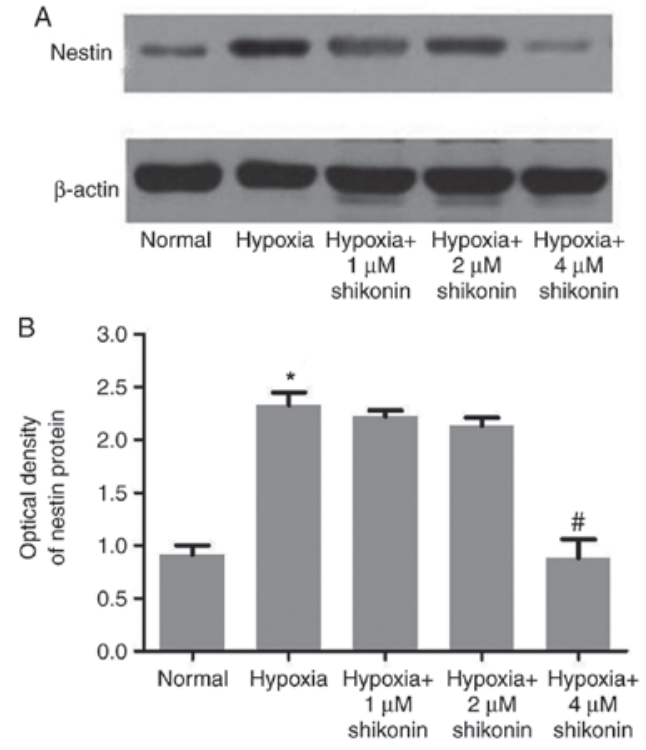

Figure 3. Effects of hypoxia and shikonin on the expression of the NES protein in PASMCs. PASMCs were cultured for $24 \mathrm{~h}$ in normoxic or hypoxic $\left(5 \% \mathrm{O}_{2}\right)$ conditions in the presence and absence of shikonin. The protein expression of NES was measured using western blotting. (A) Representative image and (B) quantification of data. ${ }^{*} \mathrm{P}<0.01$ vs. the normal and ${ }^{\#} \mathrm{P}<0.01$ vs. the hypoxia groups, $n=3$. PASMCs, pulmonary artery smooth muscle cell; NES, nestin.

The contractile phenotype, the synthetic phenotype and a transitional phenotype between the other two phenotypes (27). Of these three phenotypes, only the synthetic phenotype can be stimulated with mitogens to initiate proliferation (27). In hypoxic conditions, PASMCs transform from the contractile to the synthetic phenotype and migrate from the medial to the intimal layer to increase proliferation. Migration leads to medial thickening of the pulmonary artery and the muscularization of non-muscular vessels. These effects lead to luminal narrowing, increased resistance to blood flow and a weakened buffering effect in the pulmonary vessels, which causes alterations in blood volume and resistance (2). Therefore, these processes serve an important role in pulmonary vascular remodeling. In the present study, rat PASMCs subjected to hypoxic conditions demonstrated an increase in proliferation, which was consistent with the studies described above. 
A
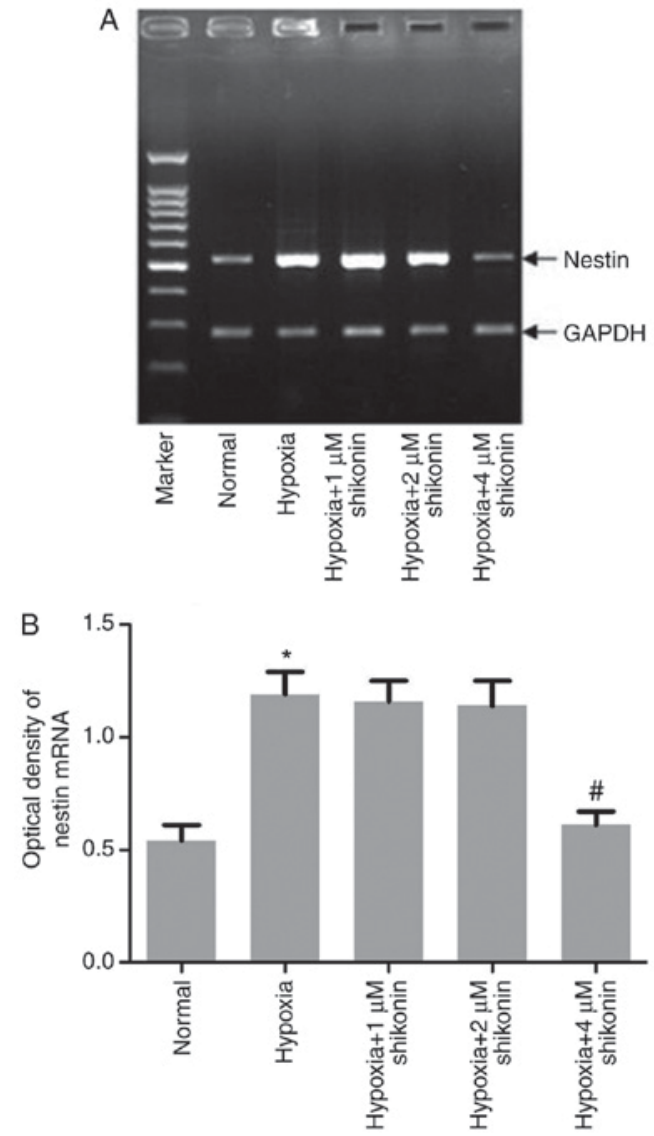

Figure 4. Effects of hypoxia and shikonin on expression of NES mRNA in PASMCs. PASMCs were cultured for $24 \mathrm{~h}$ in normoxic or hypoxic $\left(5 \% \mathrm{O}_{2}\right)$ conditions in the presence and absence of shikonin and the mRNA expression of NES was measured using reverse transcription-polymerase chain reaction. (A) Representative image and (B) quantification of data. "P $<0.01$ vs. the normal and ${ }^{\#} \mathrm{P}<0.01$ vs. the hypoxia groups, $\mathrm{n}=6$. PASMCs, pulmonary artery smooth muscle cells; NES, nestin.
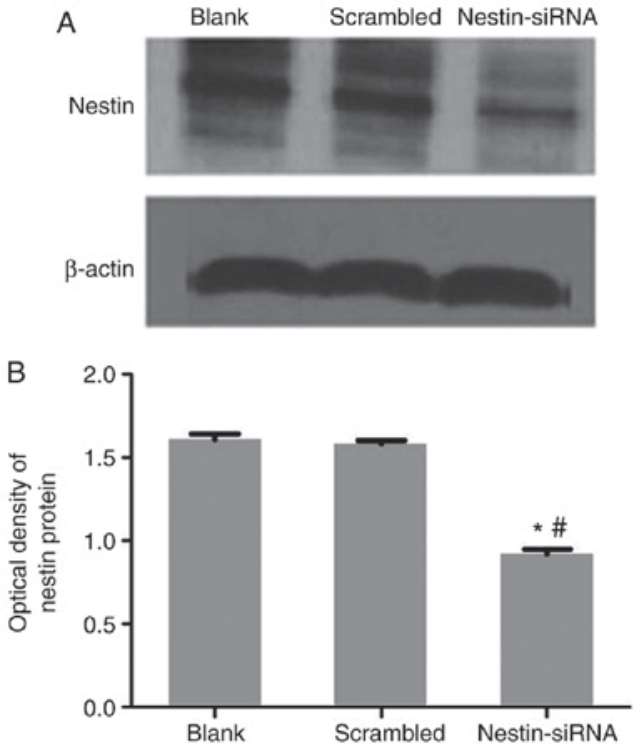

Figure 5. Effect of transfection of scrambled or NES siRNA on expression of NES protein in PASMCs. PASMCs were transfected with NES siRNA or scrambled siRNA for $48 \mathrm{~h}$ and the protein expression of NES was measured using western blotting analyses. (A) Representative image and (B) quantification of data. ${ }^{*} \mathrm{P}<0.01$ vs. the blank and ${ }^{\#} \mathrm{P}<0.01$ the scrambled groups, $\mathrm{n}=3$. siRNA, short-interfering RNA; PASMCs, pulmonary artery smooth muscle cells; NES, nestin.

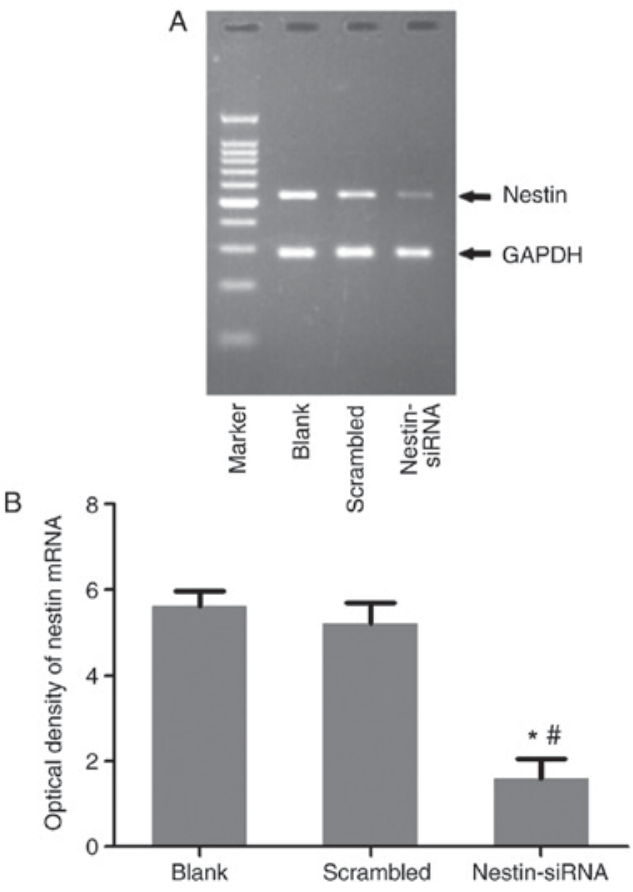

Figure 6. Effect of transfection of scrambled or NES siRNA on mRNA expression of NES in PASMCs. PASMCs were transfected with NES siRNA or scrambled siRNA for $48 \mathrm{~h}$. The mRNA expression of NES was measured using reverse transcription-polymerase chain reaction. (A) Representative image and (B) quantification of data. ${ }^{*} \mathrm{P}<0.01$ vs. the blank and ${ }^{\#} \mathrm{P}<0.01 \mathrm{vs}$. scrambled groups, $\mathrm{n}=6$. siRNA, short-interfering RNA; PASMCs, pulmonary artery smooth muscle cells; NES, nestin.

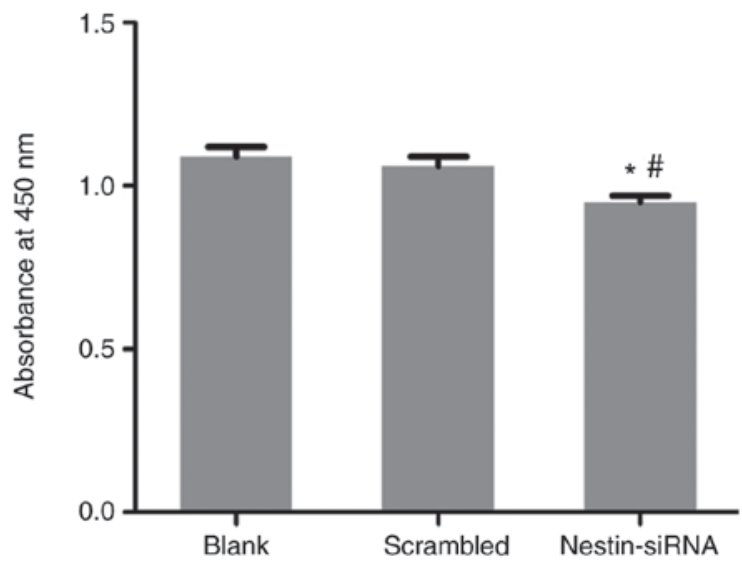

Figure 7. Effect of scrambled or NES siRNA transfection on cell viability. PASMCs were transfected with NES siRNA or scrambled siRNA for $48 \mathrm{~h}$. The cell viability was analyzed using a Cell Counting Kit. ${ }^{*} \mathrm{P}<0.01$ vs. the blank and ${ }^{~} \mathrm{P}<0.01$ vs. the scrambled groups, $n=6$. PASMCs, pulmonary artery smooth muscle cells; si, small interfering; NES, nestin.

Current investigations on the role of NES in SMCs are limited, with even fewer studies on its function in the lungs: Only a handful of studies have reported the expression of NES in human fetal lung fibroblasts and adult bronchial fibroblasts (28) however increased expression of NES in the stellate SMCs of coronary artery plaques from patients with unstable angina is frequently observed (29). These results indicate the important role of NES in the formation of coronary atherosclerotic plaques. A previous study indicated that serum stimulation restores the expression of NES 
in aortic SMCs through triggering the epidermal growth factor (EGF)-mediated extracellular signal-regulated kinase (ERK) pathway (30). The stimulation of the ERK pathway may be responsible for the alterations in the cellular phenotype $(5,30,31)$. The expression of NES in developing arteries has been observed to diminish in mature arteries (5), which indicates that NES expression is time- and region-dependent. The expression of NES is restored during the formation of carotid neointima post-balloon injury and increases gradually with neointimal proliferation (32). Therefore, NES may serve an important role in vascular remodeling. An in vitro study identified that hypoxia induces the cellular expression of the NES protein in LLC-PK1 cells, which is accompanied by alterations in cellular morphology (32). In the present study, the increased expression of NES was confirmed in rat PASMCs by RT-PCR and western blotting analyses. Furthermore, the results indicated that hypoxia promoted the upregulation of NES mRNA and protein in PASMCs.

A previous study on ST15A neural progenitor cells reported that NES interferes with cyclin dependent kinase (Cdk)5-dependent apoptosis and exerts a protective effect on these cells (33). It was also reported that RNAi significantly downregulates NES expression in vascular SMCs, which leads to an increase in the $\mathrm{H}_{2} \mathrm{O}_{2}$-mediated apoptosis of vascular SMCs (34). Therefore, NES has anti-apoptotic effects, which may occur through the activation of the Cdk5-mediated phosphorylation of the B-cell lymphoma 2 (BCL-2)/caspase signaling pathway. Therefore, NES promotes proliferation and inhibits apoptosis. In the present study, the transfection of PASMCs with specific siRNAs resulted in the downregulation of NES expression. The results of the CCK- 8 assay indicated that cell proliferation in the RNAi-treated group was significantly decreased compared with the blank control and the scrambled negative transfection control group. Therefore, it was deduced that hypoxia enhanced the proliferation of PASMCs through the upregulation of NES expression.

Shikonin is a naphthoquinone compound extracted from L. erythrorhizon. Extensive studies conducted globally have reported the various pharmacological activities of shikonin and its derivatives. Shikonin also exerts significant inhibitory effects on the proliferation and metastasis of multiple types of tumor cells, and can exert pro-apoptotic effects (35-38). A previous study suggested that shikonin can induce cell cycle arrest in the $G_{0} / G_{1}$ phase and thereby inhibit the proliferation of rat vascular SMCs (19). In addition, it was reported that shikonin induces cell-cycle arrest and apoptosis in human epidermoid carcinoma cells in a time- and dose-dependent manner (39). The apoptosis of these cells is partly mediated by the inactivation of nuclear factor $(\mathrm{NF})-\kappa \mathrm{B}$, which occurrs through the modulation of the EGF receptor signaling pathway and the activation of caspases. The study by Zhang et al (40) demonstrated that shikonin regulates the activation of the NF- $\kappa \mathrm{B}$ and phosphatidyl inositol 3-kinase signaling pathways. Shikonin also modulates the expression of cyclin D1, cyclin E, BCL-2 and BCL2 associated X protein, activates caspase- 3 and caspase-9, induces cell cycle arrest, and promotes the apoptosis of VSMCs. In the current study, rat PASMCs cultured in hypoxic conditions treated with shikonin were evaluated by a CCK- 8 assay to determine the viability of PASMCs. The results indicated that shikonin inhibited hypoxia-induced
PASMC proliferation in a dose-dependent manner. Significant inhibition of cell growth was observed following the addition of $4 \mu \mathrm{M}$ shikonin and resulted in decreased cell viability compared with the normal group. The effect of the various doses of shikonin were evaluated by RT-PCR and western blotting, and it was determined that shikonin downregulated the hypoxia-induced expression of NES in PASMCs in a dose-dependent manner. However, as it was unclear which signaling pathways were involved in the shikonin-mediated inhibition of NES in hypoxic PASMCs, further studies are required.

In conclusion, significant upregulation of NES occurred in PASMCs cultured in hypoxic conditions in vitro. NES exerted protective effects on PASMCs and promoted their proliferation. Furthermore, shikonin inhibited the proliferation of PASMCs through the downregulation of NES expression. Therefore, the present study provided information to suggest a theoretical basis for the use of shikonin in the clinical management of hypoxic $\mathrm{PH}$.

\section{Acknowledgements}

Not applicable.

\section{Funding}

No funding was received.

\section{Availability of data and materials}

All data generated or analyzed during this study are included in this published article.

\section{Authors' contributions}

SH and JF conceived the study and designed the experiments. SH and JL performed the experiments. SH and JF wrote the manuscript. JL, LL and YX analyzed the data. All authors read and approved the final manuscript.

\section{Ethics approval and consent to participate}

All experiments were performed in accordance with the National Institutes of Health Guide for the Care and Use of Laboratory Animals (NIH publication no. 80-23). The use of animals was conducted in strict accordance with Guidance Suggestions for the Care of Laboratory Animals published by the Chinese Ministry of Science and Technology. All efforts were made to minimize animal suffering and to reduce the number of animals used in the study. In addition, all animal procedures in the present study were performed in accordance with the guidelines of Wenzhou Medical University and the National Institutes of Health standards of animal care. Our study was approved by the Animal Ethics Committee of Wenzhou Medical University, including permit number SCXK (Zhejiang 2005-0019 150).

\section{Patient consent for publication}

Not applicable. 


\section{Competing interests}

The authors declare that they have no competing interests.

\section{References}

1. Stenmark KR and McMurtry IF: Vascular remodeling versus vasoconstriction in chronic hypoxic pulmonary hypertension: A time for reappraisal? Circ Res 97: 95-98, 2005.

2. Stenmark KR, Fagan KA and Frid MG: Hypoxia-induced pulmonary vascular remodeling: Cellular and molecular mechanisms. Circ Res 99: 675-691, 2006.

3. Lendahl U, Zimmerman LB and McKay RD: CNS stem cells express a new class of intermediate filament protein. Cell 60: $585-595,1990$

4. Kachinsky AM, Dominov JA and Miller JB: Intermediate filaments in cardiac myogenesis: Nestin in the developing mouse heart. J Histochem Cytochem 43: 843-847, 1995.

5. Oikawa H, Hayashi K, Maesawa C, Masuda T and Sobue K: Expression profiles of nestin in vascular smooth muscle cells in vivo and in vitro. Exp Cell Res 316: 940-950, 2010.

6. El-Helou V, Chabot A, Gosselin H, Villeneuve L, Clavet-Lanthier ME, Tanguay JF, Enikolopov G, Fernandes KJ Jasmin JF and Calderone A: Cardiac resident nestin(+) cells participate in reparative vascularisation. J Cell Physiol 228: 1844-1853, 2013

7. Ishiwata T, Matsuda Y and Naito Z: Nestin in gastrointestinal and other cancers: Effects on cells and tumor angiogenesis World J Gastroenterol 17: 409-418, 2011.

8. Béguin PC, Gosselin H, Mamarbachi M and Calderone A: Nestin expression is lost in ventricular fibroblasts during postnatal development of the rat heart and re-expressed in scar myofibroblasts. J Cell Physiol 227: 813-820, 2012.

9. Sejersen T and Lendahl U: Transient expression of the intermediate filament nestin during skeletal muscle development. J Cell Sci 106: 1291-1300, 1993.

10. Vaittinen S, Lukka R, Sahlgren C, Hurme T, Rantanen J, Lendahl U, Eriksson JE and Kalimo H: The expression of intermediate filament protein nestin as related to vimentin and desmin in regenerating skeletal muscle. J Neuropath Exp Neur 60: 588-597, 2001

11. Frisén J, Johansson CB, Török C, Risling M and Lendahl U: Rapid, widespread, and longlasting induction of nestin contributes to the generation of glial scar tissue after CNS injury. J Cell Biol 131: 453-464, 1995.

12. Daniel C, Albrecht H, Lüdke A and Hugo C: Nestin expression in repopulating mesangial cells promotes their proliferation. Lab Invest 88: 387-397, 2008.

13. Hisa T, Kimura Y, Takada K, Suzuki F and Takigawa M Shikonin, an ingredient of Lithospermum erythrorhizon, inhibits angiogenesis in vivo and in vitro. Anticancer Res 18: 783-790, 1998.

14. Chen X, Yang L, Oppenheim JJ and Howard MZ: Cellular pharmacology studies of shikonin derivatives. Phytother Res 16 : 199-209, 2002.

15. Papageorgiou VP, Assimopoulou AN and Ballis AC: Alkannins and shikonins: A new class of wound healing agents. Curr Med Chem 15: 3248-3267, 2008.

16. Tanaka S, Tajima M, Tsukada M and Tabata M: A comparative study on anti-inflammatory activities of the enantiomers, shikonin and alkannin. J Nat Prod 49: 466-469, 1986.

17. Sankawa U, Ebizuka Y, Miyazaki T, Isomura Y and Otsuka H: Antitumor activity of shikonin and its derivatives. Chem Pharm Bull (Tokyo) 25: 2392-2395, 1977.

18. Jang SY, Hong D, Jeong SY and Kim JH: Shikonin causes apoptosis by up-regulating p73 and down-regulating ICBP90 in human cancer cells. Biochem Biophys Res Commun 465: 71-76, 2015.

19. Zhang ZQ, Cao XC, Zhang L and Zhu WL: Effect of shikonin, a phytocompound from Lithospermum erythrorhizon, on rat vascular smooth muscle cells proliferation and apoptosis in vitro. Zhonghua Yi Xue Za Zhi 85: 1484-1488, 2005 (In Chinese).

20. Liu J, Da ZK, Li Z, Xue YX, Liu LB, Wang P and Liu YH: Effects of shikonin on sternness maintance of glioma stem cells. Chin Pharmacol Bull 1: 49-54, 2016.

21. García-Blanco A, Bulnes S, Pomposo I, Carrasco A and Lafuente JV: Nestin+cells forming spheroids aggregates resembling tumorspheres in experimental ENU-induced gliomas. Histol Histopathol 31: 1347-1356, 2016.
22. National Institutes of Health (NIH): Guide for the Care and Use of Laboratory Animals. The National Academies Press, Washington D.C., 1996.

23. He ZM, Li GP, Zhu DS and Lu SM: Guidelines for the management and use of experimental animals. State Science and Technology Academic Publication Fund Committee and Science and Technology Press, Beijing, pp80-115, 2016

24. Gunther S, Alexander RW, Atkinson WJ and Gimbrone MA Jr: Functional angiotensin II receptors in cultured vascular smooth muscle cells. J Cell Biol 92: 289-298, 1982.

25. Nagamoto T, Eguchi G and Beebe DC: Alpha-smooth muscle actin expression in cultured lens epithelial cells. Invest Ophthalmol Vis Sci 41: 1122-1129, 2000.

26. Hawryłkiewicz I: Hypoxic pulmonary hypertension-chronic cor pulmonale. Pneumonol Alergol Pol 71: 562-568, 2003

27. Archer SL, Huang JM, Reeve HL, Hampl V, Tolarová S, Michelakis E and Weir EK: Differential distribution of electrophysiologically distinct myocytes in conduit and resistance arteries determines their response to nitric oxide and hypoxia. Circ Res 78: 431-442, 1996.

28. Sabatini F, Petecchia L, Tavian M, Jodon de Villeroché V, Rossi GA and Brouty-Boyé D: Human bronchial fibroblasts exhibit a mesenchymal stem cell phenotype and multilineage differentiating potentialities. Lab Invest 85: 962-971, 2005.

29. Suguta M, Nakano A, Hoshino Y, Endoh M, Hatori T, Hasegawa A, Aihara M, Takeuchi T and Kurabayashi M: Nestin, a maker for multilineage potential of cells from human primary and restenotic coronary artery plaques. Int J Cardiol 121: 53-56, 2007.

30. Huang YL, Shi GY, Jiang MJ, Lee H, Chou YW, Wu HL and Yang HY: Epidermal growth factor up-regulates the expression of nestin through the Ras-Raf-ERK signaling axis in rat vascular smooth muscle cells. Biochem Biophys Res Commun 377: 361-366, 2008

31. Huang YL, Shi GY, Lee H, Jiang MJ, Huang BM, Wu HL and Yang HY: Thrombin induces nestin expression via the transactivation of EGFR signalings in rat vascular smooth muscle cells. Cell Signal 21: 954-968, 2009.

32. Saboor F, Reckmann AN, Tomczyk CU, Peters DM, Weissmann N, Kaschtanow A, Schermuly RT, Michurina TV, Enikolopov G, Müller D, et al: Nestin-expressing vascular wall cells drive development of pulmonary hypertension. Eur Respir J 47: 876-888, 2016.

33. Sakairi T, Hiromura K, Yamashita S, Takeuchi S, Tomioka M, Ideura H, Maeshima A, Kaneko Y, Kuroiwa T, Nangaku M, et al: Nestin expression in the kidney with an obstructed ureter. Kidney Int 72: 307-318, 2007.

34. Sahlgren CM, Pallari HM, He T, Chou YH, Goldman RD and Eriksson JE: A nestin scaffold links Cdk5/p35 signaling to oxidant-induced cell death. Embo J 25: 4808-4819, 2006.

35. Huang YL, Wu CM, Shi GY, Wu GC, Lee H, Jiang MJ, Wu HL and Yang HY: Nestin serves as a prosurvival determinant that is linked to the cytoprotective effect of epidermal growth factor in rat vascular smooth muscle cells. J Biochem 146: 307-315, 2009.

36. Singh F, Gao D, Lebwohl MG and Wei H: Shikonin modulates cell proliferation by inhibiting epidermal growth factor receptor signaling in human epidermoid carcinoma cells. Cancer Lett 200: 115-121, 2003.

37. Chen CH, Chern CL, Lin CC, Lu FJ, Shih MK, Hsieh PY and Liu TZ: Involvement of reactive oxygen species, but not mitochondrial permeability transition in the apoptotic induction of human SK-Hep-1 hepatoma cells by shikonin. Planta Med 69: 1119-1124, 2003

38. Min R, Tong J, Wenjun Y, Wenhu D, Xiaojian Z, Jiacai H, Jian Z, Wantao $\mathrm{C}$ and Chenping Z: Growth inhibition and induction of apoptosis in human oral squamous cell carcinoma Tca-8113 cell lines by Shikonin was partly through the inactivation of NF-kappaB pathway. Phytother Res 22: 407-415, 2008.

39. Tian R, Li Y and Gao M: Shikonin causes cell-cycle arrest and induces apoptosis by regulating the EGFR-NF- $\kappa \mathrm{B}$ signalling pathway in human epidermoid carcinoma A431 cells. Biosci Rep 35: pii: e00189, 2015.

40. Zhang $\mathrm{X}, \mathrm{Hu}$ W, Yuan $\mathrm{X}$ and $\mathrm{Hu} \mathrm{J}$ : Shikonin inhibits TNF- $\alpha$-induced growth and invasion of rat aortic vascular smooth muscle cells. Can J Physiol Pharmacol 93: 615-624, 2015. 